\title{
Neurological manifestations found in children with multisystem inflammatory syndrome
}

\author{
CRISTINA MARIA MIHAI ${ }^{1}$, TATIANA CHISNOIU ${ }^{1}$, CLAUDIA SIMONA CAMBREA ${ }^{2}$, \\ CORINA ELENA FRECUS ${ }^{1}$, LARISIA MIHAI $^{1}$, ADRIANA LUMINITA BALASA ${ }^{1}$, \\ ALINA ZORINA STROE ${ }^{3}$, ANCA ELENA GOGU ${ }^{4}$ and ANY DOCU AXELERAD ${ }^{3}$ \\ Departments of ${ }^{1}$ Pediatrics, ${ }^{2}$ Infectious Diseases and ${ }^{3}$ Neurology, Faculty of General Medicine, \\ 'Ovidius' University of Constanta, 900470 Constanta; ${ }^{4}$ Department of Neurology, \\ ‘Victor Babes' University of Medicine and Pharmacy, 300041 Timisoara, Romania
}

Received October 18, 2021; Accepted November 17, 2021

DOI: $10.3892 /$ etm.2022.11187

\begin{abstract}
The pandemic that resulted from the spread of SARS-CoV-2 viral infections has affected the population worldwide but has characteristically shown a preponderance for affecting adults. However, cases of SARS-CoV-2 infection have been reported in children, showing a systemic echo and severe damage. Multisystem inflammatory syndrome in children (MIS-C) can occur, on average, 4 weeks after the infection of a child with SARS-CoV-2. The aim of the present study was to examine 30 cases of children affected by MIS-C in terms of symptoms, laboratory tests, and evolution. Patients included in the study presented with neurological symptomatology including headache, meningism, and drowsiness. Treatment was administered in concordance with the protocol for MIS-C. The evolution of the patients in the present study was favorable and the symptomatology remitted in days to weeks. The importance of identifying the features of this disease, its treatment, and that the most probable evolution is favorable is significant in the medical world, especially as the pandemic is ongoing.
\end{abstract}

\section{Introduction}

A worldwide pandemic was triggered with the manifestation of the SARS-CoV-2 virus (COVID-19). Millions of individuals have since succumbed and millions more have been

Correspondence to: Dr Alina Zorina Stroe, Department of Neurology, Faculty of General Medicine, 'Ovidius' University of Constanta, 1 Aleea Universității Street, 900470 Constanta, Romania E-mail: zorina.stroe@yahoo.com

Abbreviations: MIS-C, multisystem inflammatory syndrome in children; PICU, pediatric intensive care unit; KD, Kawasaki disease; $\mathrm{Ab}$, antibody; CT, computed tomography

Key words: multisystem inflammatory syndrome in children, SARS-COV2, coronavirus infection, pediatrics infected (1). Fever, cough, shortness of breath, tiredness, and malaise are the primary clinical symptoms of this disease in adults (2). Although infections in children were considerably fewer than in adults at the start of the epidemic, with the introduction of quarantine and spending time only indoors, more cases began to appear in children who came into close contact with infected family members (3).

Despite the rise of the COVID-19 pandemic in Asia and its rapid spread across the globe, doctors were relieved that the virus affected the majority of children with minor symptoms (4). However, in April 2020, the United Kingdom's National Health Service issued a warning regarding cases of school-aged children and adolescents with fever, hypotension, severe abdominal pain, and cardiac dysfunction who screened positive for SARS-CoV-2 infection via a nasopharyngeal RT-PCR or antibody (Ab) test (4). Due to their elevated levels of interleukin (IL)-6, these patients often needed inotropic support to improve cardiac output, with just a few needing extracorporeal membrane ventilation. After a few days, the majority of the children were no longer in need of critical care and had completely recovered. However, a few children succumbed as a result of complications associated with extracorporeal membrane oxygenation $(3,4)$.

Young patients with acute COVID-19 infection may be asymptomatic or they may have a fever, cough, nasal congestion, and/or digestive symptoms (4), and often do not require hospitalization. However, in some cases, children may develop a multisystemic inflammatory syndrome after becoming infected with the SARS-CoV-2 virus, a condition that has been termed multisystem inflammatory syndrome in children (MIS-C). Throughout the UK (5), Italy (6), Spain (7), France (8), Switzerland (8), and the US (8), the Centers for Disease Control and Prevention developed a case definition for use in the US and termed it MIS-C.

During the SARS-CoV-2 virus pandemic, pediatricians observed fever and multisystem inflammation as being present in hospitalized children. In several cases, the patients were severely affected with multiorgan shock and collapse that necessitated intensive care, and several cases presented with characteristics of Kawasaki disease (KD) or KD shock syndrome $(6,8-10)$. 
Between 3 March and 14 April 2020, only 48 children required admission to a pediatric intensive care unit (PICU), according to an early retrospective research assessing pediatric outcomes at 46 pediatric institutions throughout North America (11). The United Kingdom's Pediatric Intensive Care Society issued a warning about an increase in the number of children presenting with a multisystem inflammatory disease resembling KD or toxic shock syndrome, with many children testing positive for COVID-19 (12). The New York State Department of Health reported 15 first cases with symptoms consistent with those described above on 4 May 2020, and by 17 May 2020, 145 suspected cases had been recorded in New York state hospitals (11).

MIS-C has been detected in a number of nations affected by the COVID-19 pandemic. Starting from the spring of 2020, the above disease has been referred to as a Kawasaki-like disease in Western nations (5). MIS-C is a hyperinflammatory condition that can progress to macrophage activation syndrome, or cytokine storm, as reported by Kabeerdoss et al (13). Neurological manifestations that correlated with SARS-CoV-2 infection present in adults included encephalitis, meningitis, encephalopathy, stroke, seizures, and anosmia (14). However, there were limited instances of neurological symptoms associated with SARS-CoV-2 infection in children (15).

The aim of the present study was to examine 30 cases of children affected by MIS-C in terms of symptoms, laboratory tests, and evolution. The evolution of the disease was favorable, which is encouraging for the medical field.

\section{Patients and methods}

Ethics and consent. A retrospective, observational, descriptive study was conducted between August 2020 and May 2021 in the Pediatrics Clinic of Constanta County Emergency Hospital. The present study was authorized by the Ethics Committee of the Constanta Clinical Hospital in Romania (no. 24/22.07.2020), and all the guardians completed an informed consent form. All measures to ensure the safety of hospital staff were adhered to.

Inclusion and exclusion criteria. The inclusion criteria for the study were patients with signs, symptoms, and elevated laboratory markers who met the CDC case definition criteria for MIS-C, and who presented with multisystemic and neurological impairment. The exclusion criterion was the existence of a pre-existing neurological condition.

Patient data. The study included 30 patients of age ranging for both boys and girls between 8 months and 15 years. The laboratory data, imaging studies including a craniocerebral MRI, and confirmation of SARS-CoV-2 infection via igG anti-SARS-CoV-2 antibodies (method: microparticle chemiluminescence, CMIA), therapy, and evolution were collected for each patient.

\section{Results}

General. In the present study, 30 patients with MIS-C were identified, of whom 14 had neurological manifestations. Of these 14,10 patients $(71 \%)$ were male.
Table I. Symptoms of the study group with MIS-C.

\begin{tabular}{lc}
\hline Symptoms & No. of patients \\
\hline Headache & 11 \\
Ataxia & 5 \\
Photophobia & 5 \\
Difficulty walking & 4 \\
Meningism & 9 \\
Diplopia & 1 \\
New appeared strabismus & 1 \\
Drowsiness & 7 \\
Lethargy & 5 \\
Alteration of consciousness & 6 \\
Skin hyperaesthesia & 6
\end{tabular}

MIS-C, multisystem inflammatory syndrome in children.

Symptoms experienced by MIS-C patients. The most common neurological manifestations in MIS-C were headache (11 cases), meningism (9 cases), and drowsiness ( 7 cases). Skin hyperesthesia and altered consciousness were reported in 6 patients. Patients experienced photophobia, ataxia, and lethargy in 5 cases, respectively. One patient from each of the studied groups presented new diplopia and strabismus, and subsequently a craniocerebral MRI was performed, from which demyelinating lesions were detected. The symptomatology is described in Table I.

Clinical features. According to the treatment protocol from MIS-C, all patients in the study group received human immunoglobulin IV at a dose of $2 \mathrm{~g} / \mathrm{kg}$ for a single administration and acetylsalicylic acid at a dose between 3 and $5 \mathrm{mg} / \mathrm{kg} /$ day. In addition, methylprednisolone was administered to 5 patients at a dose of $3 \mathrm{mg} / \mathrm{kg} /$ day and 7 patients at a dose of $5 \mathrm{mg} / \mathrm{kg} / \mathrm{day}$. The detailed information of some cases is provided in Table II. No patient required inotropic medication.

\section{Discussion}

$M I S-C$. MIS-C following SARS-CoV-2 infection is characterized by persistent fever, increased inflammatory markers, and multisystemic impairment (16). MIS-C can occur, on average, 4 weeks after infection of a child with SARS-CoV-2. The child may have acquired the virus via an asymptomatic contact, and in certain instances, the youngster and their family may be unaware they have been infected. Multisystem damage most often includes heart, mucocutaneous, gastrointestinal, and neurological damage.

The report by Abdel-Mannan et al in April 2020 described $52 \%$ of neurological symptoms associated with MIS-C, including headache, lethargy, altered consciousness, encephalopathy, dysarthria/dysphonia, hallucinations, ataxia, and convulsions (17).

Neurological manifestations in MIS-C are common and often include headache, lethargy, confusion, and irritability. More severe neurological manifestations, such as 


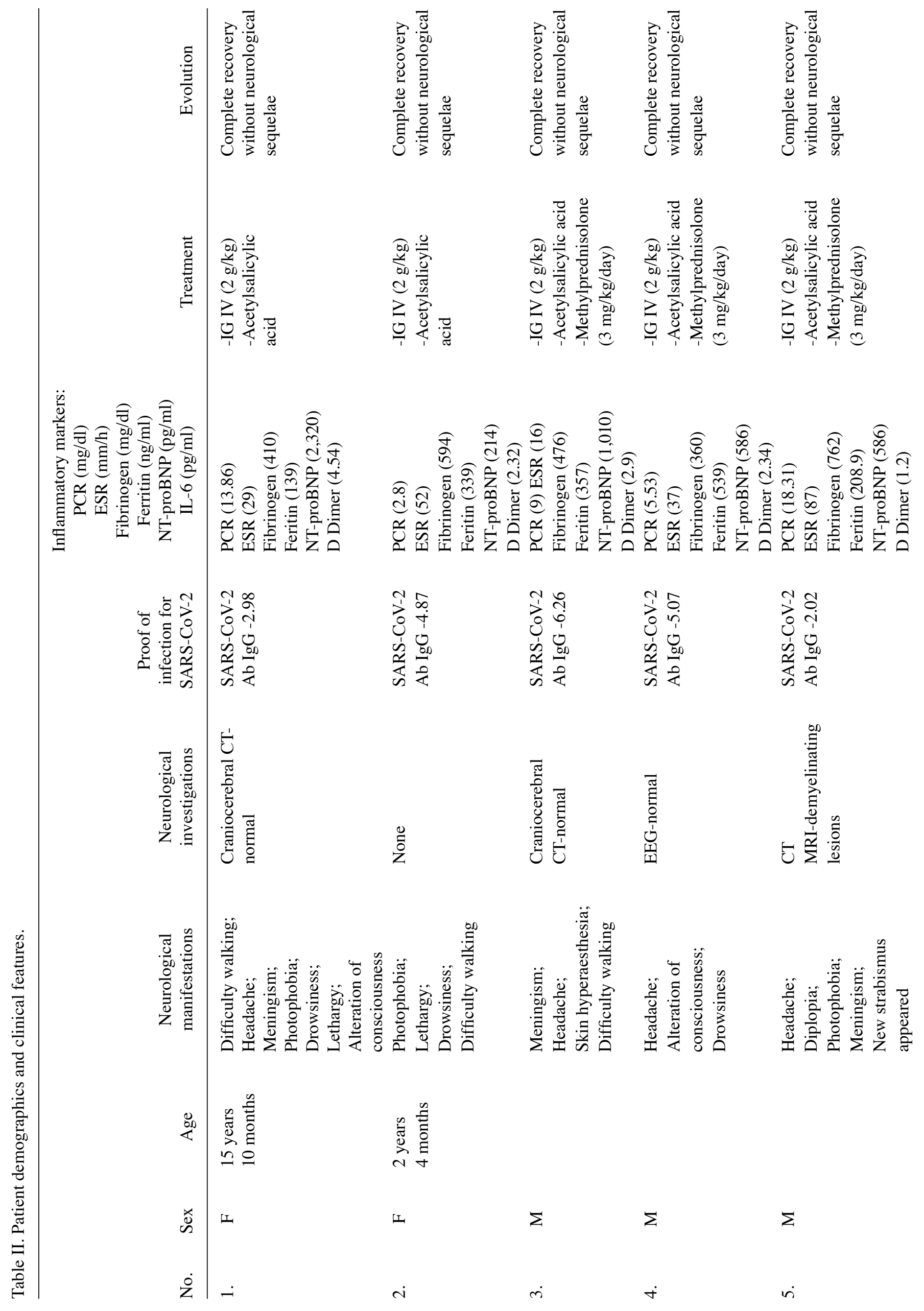




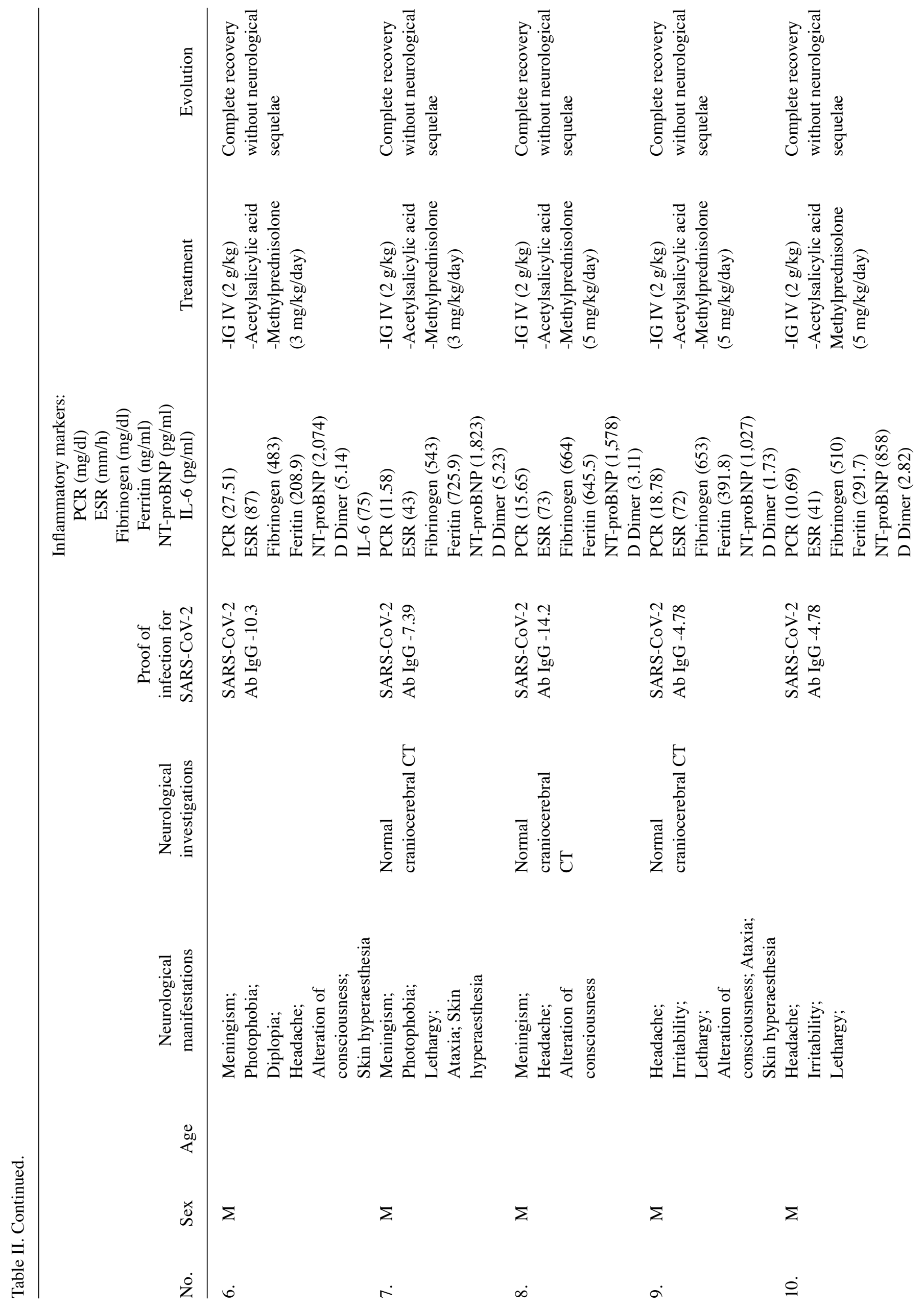




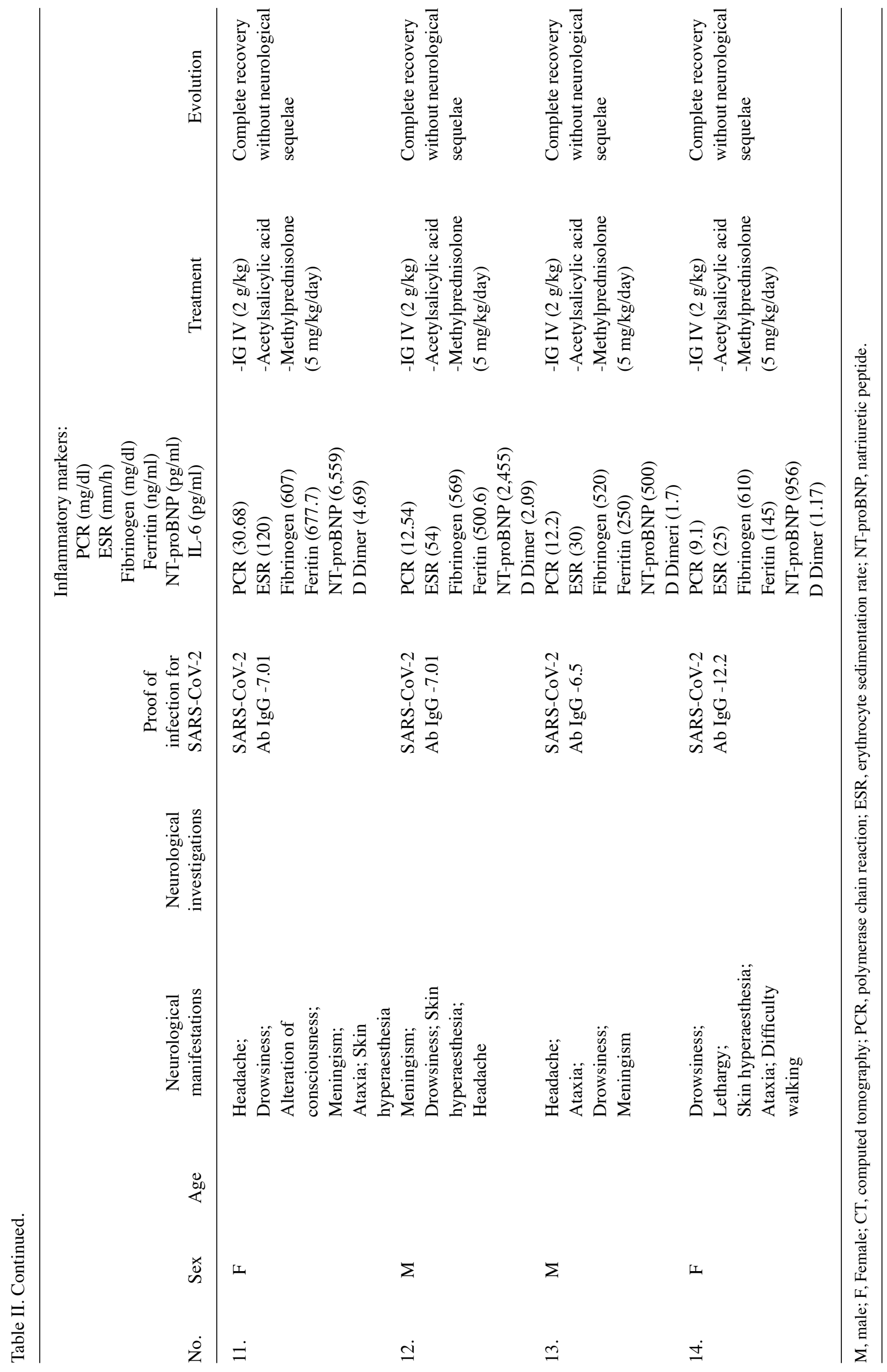


encephalopathy, seizures, coma, stroke, meningoencephalitis, and meningitis, occur at a much smaller percentage, as recently reported $(17,18)$.

A study conducted in the US showed that of 616 patients with MIS-C, 20\% had neurological manifestations (19). In addition, severe, life-threatening neurological disorders occurred in 20 patients (3\%), including severe encephalopathy, demyelinating lesions, stroke, acute cerebral edema, and Guillain-Barre syndrome.

In the present study, treatment was provided according to the current recommendations of the international treatment guidelines for MIS-C with immunoglobulin, methylprednisolone, and acetylsalicylic acid. The evolution was favorable in all cases, with recovery without neurological sequelae. In adults, human plasmapheresis or intravenous immunoglobulin was reported to be beneficial for neuroinflammatory complications, including COVID-19-linked autoimmune meningoencephalitis (20). In children, the therapeutic effect of plasmapheresis remains unclear. All the patients with MIS-C who received intravenous immunoglobulin and/or methylprednisolone fully recovered without neurological sequelae (21).

Cheung et al (22) included 17 patients in their study, all of whom presented fever, 14 presented gastrointestinal symptoms of whom the majority presented mucocutaneous findings, and 13 patients experienced shock. All 17 patients had increased levels of inflammatory markers, the majority having lymphopenia, and all were positive for SARS-CoV-2 infection. There were no deaths among the patients and they were all released (21).

Until the end of April 2020, SARS-CoV-2 infection in children was believed to be asymptomatic or to produce moderate febrile sickness (23). Riollano-Cruz et al (23) described 15 pediatric COVID-19 patients that manifested symptoms consistent with a multisystemic hyperinflammatory syndrome that overlapped several characteristics with well-characterized systemic inflammatory diseases. Not all patients tested positive for SARS-CoV-2 through molecular testing of nasopharyngeal specimens in their research. However, all the patients tested positive for SARS-CoV-2 in lower respiratory specimen test, indicating that, although COVID-19 infection produced this symptomatology, the hyperinflammatory condition observed in these children was probably triggered by a post-infectious cytokine storm instead of direct viral replication-induced cell damage.

The relative absence of pulmonary findings in pediatric COVID-19 cases compared to adults raises further concerns regarding pathogenesis, since pulmonary involvement does not appear to be the main source of dysfunction in SARS-CoV-2 infection in children (24). Brown et al (24) reported infiltration

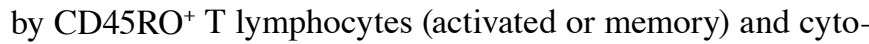
toxic $\mathrm{CD}^{+} \mathrm{T}$ lymphocytes in coronary artery aneurysms from patients with fatal acute coronary arteritis KD, concluding that this finding suggests the existence of an intraepithelial pathogen, most probably viral, continuing to support an endothelium-mediated cause. Varga et al (25) recently reported the presence of virus-like particles in endothelial cells and endotheliitis in COVID-19 patient tissues. Endothelial cell dysfunction caused by direct viral infection may account for the poor systemic microcirculatory function observed in COVID-19 patients.
There have been documented differences in disease outcomes across races and ethnic groups following SARS-CoV-2 infection, with individuals of African descent (21), African Americans (22), Hispanics (23), and individuals from Latin America (24) experiencing more severe sickness, hospitalizations, and fatalities. The lineage of COVID-associated MIS-C patients demonstrated the essential nature of preventing viral transmission in this age range.

Differences between the KD and MIS-C. Doctors have identified clinical parallels between MIS-C and KD, a febrile disease that occurs in early infancy and leads to inflammation of the blood vessels, which may result in coronary artery aneurysms (25). Patients with MIS-C may exhibit comparable symptoms to those with KD, including fever, dilated conjunctival vessels, rash, and oropharyngeal erythema $(25,26)$. Nevertheless, these clinical signs are not diagnosis-specific and may be identified in a variety of infectious diseases in children.

In the last 50 years, the epidemiology of KD has been documented globally, with 80 percent of cases occurring in children under the age of five years and a peak incidence at 10 months of age. This is in striking contrast to the epidemiology of MIS-C, a disease that mostly affects older children and adolescents. Laboratory data consistent with MIS-C, such as leukopenia and extremely high ventricular natriuretic peptide values, were not consistent with KD. Asian children have the greatest prevalence of KD worldwide, while African-born children are more susceptible to MIS-C. In China or Japan, no instances of MIS-C have been reported (26). Both diseases have very distinct epidemiologies. While SARS-CoV-2 has not been definitively linked to MIS-C, the observation that MIS-C occurred during COVID-19 outbreaks in Europe and the US supports this theory.

Link between MIS-C and SARS-CoV-2. Whether or not MIS-C is associated with SARS-CoV-2 infection, the pathophysiological mechanism of the disease remains unclear. Other authors have suggested that, MIS-C is not the consequence of acute viral infection, but rather a post-infectious phenomenon associated with exacerbation of the disease mediated by $\mathrm{IgG}$ antibodies $(25,26)$. This phenomenon occurs for two main reasons. First, MIS-C cases have been delayed in certain regions relative to the peak of SARS-CoV-2 infection. Due to the likelihood that children may become infected with the virus owing to exposure to infected parents as a result of home limitations, the maximum number of cases is extended. Interestingly, children with MIS-C often appear with gastrointestinal symptoms and have minimal, if any, respiratory symptoms. As a result, the virus may spread mostly via the gastrointestinal system. Enterocytes have been found to be susceptible to infection by SARS-CoV-2, and patients with MIS-C who have had exploratory laparotomy exhibit mesenteric adenitis, which facilitates gastrointestinal infection. This has not been observed in children suffering with MIS-C (27). Furthermore, the development of antibodies against SARS-CoV-2 does not always suggest a post-infectious phase, since antibodies may develop as early as the second week after infection.

There is a dearth of information on the specificity of $\mathrm{Ab}$ tests conducted on individuals with MIS-C, which may vary significantly. As SARS-CoV-2 infection spreads across 
a community and most children remain asymptomatic or slightly symptomatic, positive Ab tests may be more prevalent, and child screening may be needed to demonstrate a positive link between SARS-CoV-2 and a specific disease. It is intriguing that worsening of the disease in patients with COVID-19 treated with convalescent plasma is not yet recognized as a clinical issue, as one would anticipate if Ab-mediated enhancement represents a significant mechanism for the occurrence of severe COVID-19 complications.

Kaushik et al (28) conducted a meta-analysis of 328 publications and found that, the median period between the start of symptoms and hospital admission was four days (interquartile range, 3-6 days). The most often reported symptom was fever, being followed by gastrointestinal (GI) symptoms. Almost all investigations documented gastrointestinal signs, which were observed in 458 (70\%) individuals, with symptoms resembling viral gastroenteritis or inflammatory bowel disease, including nausea, vomiting, diarrhea, and abdominal discomfort. At presentation, 332 (51\%) individuals reported having cardiovascular symptoms. An additional 186 (28\%) individuals experienced hypotension, and 235 (36\%) patients experienced ER-like symptoms, with 41 having a conventional KD and 194 having an unusual presentation. Among patients exhibiting KD-like symptoms, 62 (26\%) developed circulatory shock (29-31). In 12 studies, the central nervous system was involved in the evolution of $145(22 \%)$ children who presented with aseptic meningitis, headache, or changed mental state (32). Approximately 8 studies documented symptoms of the respiratory system, such as coughing or constipation (33). Rash was observed in 379 (58\%) patients, hand and foot edema was mentioned in 83 (13\%) patients, conjunctival injection was noted in 263 (40\%) patients, cracked red lips were noted in $148(23 \%)$ patients, strawberry tongue was revealed in $29(4.5 \%)$ patients, and cervical lymphadenitis was identified in $27(4 \%)$ patients. In terms of presenting features reported across geographic areas, rashes were more often observed in India, whereas cardiovascular involvement was more frequently recorded in European research.

A convincing alternate theory for the prominent cytokine storm in children with MIS-C is centered on the known inhibitory activity on type I and III interferon responses of coronaviruses (34), which may also result in a delayed cytokine storm in patients with an immune system incapable of controlling the viral response or replication, or in patients with elevated initial SARS-CoV-2 viral load (35).

Panigrahy et al (36) reviewed 57 studies of 875 MIS-C patients from 15 countries, and the patients had tested positive or had an epidemiologic connection with SARS-CoV-2 infection. More boys than girls presented with symptoms, and the age of 9 years was the most prevalent in the children in this review. Almost $50 \%$ of the patients presented with other medical conditions and the most prevalent was obesity. In that study, the death rate related to MIS-C was $2.5 \%$ (36).

In summary, MIS-C is a relatively novel and understudied disease that affects children and is therefore of significant interest globally. To the best of our knowledge, this is the first study of MIS-C in Romania; consequently, the insights provided by this study are extremely valuable and significant. The evolution of the patients in the present study was favorable and the symptomatology remitted in days to weeks.

\section{Acknowledgements}

Not applicable.

\section{Funding}

Not applicable.

\section{Availability of data and materials}

The datasets used and/or analyzed during the present study are available from the corresponding author on reasonable request.

\section{Authors' contributions}

CMM, TC, CSC, CEF, LM, ALB, AZS, AEG and ADA conceived and designed the study. CMM, TC, CSC, CEF and AZS performed the literature research. CMM, TC, CSC, CEF, $\mathrm{LM}, \mathrm{ALB}, \mathrm{AZS}$ and ADA were involved in the interpretation of the results. CMM, TC, CSC, CEF, LM, ALB, AZS and ADA were involved in the writing of the manuscript. All authors have read and approved the final manuscript. CMM, TC, CSC, CEF, LM, ALB, AZS, AEG and ADA confirm the authenticity of all the raw data.

\section{Ethics approval and consent to participate}

The current study was approved by the Ethics Committee of the Constanta Clinical Hospital, Romania (no. 24/22.07.2020) and all the guardians provided informed consent and signed a statement to that effect.

\section{Patient consent for publication}

Not applicable.

\section{Competing interests}

The authors declare that they have no competing interests.

\section{References}

1. Bialek S, Boundy E, Bowen V, Chow N, Cohn A, Dowling N, Ellington S, Gierke R, Hall A, MacNeil J, et al: Severe outcomes among patients with coronavirus disease 2019 (COVID-19)United States, February 12-March 16, 2020. MMWR Morb Mortal Wkly Rep 69: 343-346, 2020.

2. Hasani H, Mardi S, Shakerian S, Taherzadeh-Ghahfarokhi N and Mardi P: The novel coronavirus disease (COVID-19): A PRISMA systematic review and meta-analysis of clinical and paraclinical characteristics. Biomed Res Int 2020: 3149020 , 2020.

3. Dong Y, Mo X, Hu Y, Qi X, Jiang F, Jiang Z and Tong S: Epidemiology of COVID-19 among children in China. Pediatrics 145: e20200702, 2020.

4. Cruz AT and Zeichner SL: COVID-19 in children: Initial characterization of the pediatric disease. Pediatrics 145: e20200834, 2020.

5. Riphagen S, Gomez X, Gonzalez-Martinez C, Wilkinson N and Theocharis P: Hyperinflammatory shock in children during COVID-19 pandemic. Lancet 395: 1607-1608, 2020.

6. Verdoni L, Mazza A, Gervasoni A, Martelli L, Ruggeri M, Ciuffreda M, Bonanomi E and D'Antiga L: An outbreak of severe Kawasaki-like disease at the Italian epicentre of the SARS-CoV-2 epidemic: an observational cohort study. Lancet 395: 1771-1778, 2020. 
7. Cabrero-Hernández M, García-Salido A, Leoz-Gordillo I, Alonso-Cadenas JA, Gochi-Valdovinos A, González Brabin A, De Lama Caro-Patón G, Nieto-Moro M, de-Azagra-Garde AM and Serrano-González A: Severe SARS-CoV-2 infection in children with suspected acute abdomen: A case series from a tertiary hospital in Spain. Pediatr Infect Dis J 39: e195-e198, 2020

8. Belhadjer Z, Méot M, Bajolle F, Khraiche D, Legendre A, Abakka S, Auriau J, Grimaud M, Oualha M, Beghetti M, et al: Acute heart failure in multisystem inflammatory syndrome in children in the context of global SARS-CoV-2 pandemic. Circulation 142: 429-436, 2020.

9. Toubiana J, Poirault C, Corsia A, Bajolle F, Fourgeaud J, Angoulvant F, Debray A, Basmaci R, Salvador E, Biscardi S, et al: Outbreak of Kawasaki disease in children during COVID-19 pandemic: A prospective observational study in Paris, France. MedRxiv: May 14, 2020 (Epub ahead of print). doi: https://doi. org/10.1101/2020.05.10.20097394.

10. Viner RM and Whittaker E: Kawasaki-like disease: Emerging complication during the COVID-19 pandemic. Lancet 395: 1741-1743, 2020.

11. Shekerdemian LS, Mahmood NR, Wolfe KK, Riggs BJ, Ross CE, McKiernan CA, Heidemann SM, Kleinman LC, Sen AI, Hall MW, et al: Characteristics and outcomes of children with coronavirus disease 2019 (COVID-19) infection admitted to US and Canadian pediatric intensive care units. JAMA Pediatr 174: $868-873,2020$

12. Flood J, Shingleton J, Bennett E, Walker B, Amin-Chowdhury Z, Oligbu G, Avis J, Lynn RM, Davis P, Bharucha T, et al: Paediatric multisystem inflammatory syndrome temporally associated with SARS-CoV-2 (PIMS-TS): Prospective, national surveillance, United Kingdom and Ireland, 2020. Lancet Reg Health Eur 3: 100075, 2021.

13. Kabeerdoss J, Pilania RK, Karkhele R, Kumar TS, Danda D and Singh S: Severe COVID-19, multisystem inflammatory syndrome in children, and Kawasaki disease: Immunological mechanisms, clinical manifestations and management. Rheumatol Int 41: $19-32,2021$.

14. Mao L, Jin H, Wang M, Hu Y, Chen S, He Q, Chang J, Hong C, Zhou Y, Wang D, et al: Neurologic manifestations of hospitalized patients with coronavirus disease 2019 in Wuhan, China. JAMA Neurol 77: 683-690, 2020.

15. Dugue R, Cay-Martínez KC, Thakur KT, Garcia JA, Chauhan LV, Williams SH, Briese T, Jain K, Foca M, McBrian DK, et al: Neurologic manifestations in an infant with COVID-19. Neurology 94: 1100-1102, 2020.

16. CDC: Multisystem inflammatory syndrome (MIS). Centers for disease control and prevention, 2021. https://www.cdc.gov/mis/ index.html. Access date: ?

17. Abdel-Mannan O, Eyre M, Löbel U, Bamford A, Eltze C Hameed B, Hemingway C and Hacohen Y: Neurologic and radiographic findings associated with COVID-19 infection in children. JAMA Neurol 77: 1440-1445, 2020.

18. Feldstein LR, Rose EB, Horwitz SM, Collins JP, Newhams MM, Son MBF, Newburger JW, Kleinman LC, Heidemann SM, Martin AA, et al: Multisystem inflammatory syndrome in U.S. Children and adolescents. N Engl J Med 383: 334-346, 2020.

19. LaRovere KL, Riggs BJ, Poussaint TY, Young CC,Newhams MM, Maamari M, Walker TC, Singh AR, Dapul H, Hobbs CV, et al: Neurologic involvement in children and adolescents hospitalized in the United States for COVID-19 or multisystem inflammatory syndrome. JAMA Neurol 78: 536-547, 2021.

20. Dogan L, Kaya D, Sarikaya T, Zengin R, Dincer A, Akinci IO and Afsar N: Plasmapheresis treatment in COVID-19-related autoimmune meningoencephalitis: Case series. Brain Behav Immun 87: 155-158, 2020.
21. Kurup S, Burgess R, Tine F, Chahroudi A and Lee DL: SARS-CoV-2 infection and racial disparities in children: Protective mechanisms and severe complications related to MIS-C. J Racial Ethn Health Disparities: Jul 13, 2021 (Epub ahead of print). doi: 10.1007/s40615-021-01092-7.

22. Cheung EW, Zachariah P, Gorelik M, Boneparth A, Kernie SG, Orange JS and Milner JD: Multisystem inflammatory syndrome related to COVID-19 in previously healthy children and adolescents in New York City. JAMA 324: 294-296, 2020.

23. Ashktorab H, Pizuomo A, González NAF, Villagrana EDC, Herrera-Solís ME, Cardenas G, Zavala-Alvarez D, Oskrochi G, Awoyemi E, Adeleye F, et al: A comprehensive analysis of COVID-19 impact in Latin America. Res Sq: rs.3.rs-141245, 2021.

24. Brown TJ, Crawford SE, Cornwall ML, Garcia F, Shulman ST and Rowley AHCD8 T lymphocytes and macrophages infiltrate coronary artery aneurysms in acute Kawasaki disease. J Infect Dis 184: 940-943, 2001.

25. Varga Z, Flammer AJ, Steiger P, Haberecker M, Andermatt R, Zinkernagel AS, Mehra MR, Schuepbach RA, Ruschitzka F and Moch H: Endothelial cell infection and endotheliitis in COVID-19. Lancet 395: 1417-1418, 2020.

26. Xu S, Chen M and Weng J: COVID-19 and Kawasaki disease in children. Pharmacol Res 159: 104951, 2020.

27. Lamers MM, Beumer J, van der Vaart J, Knoops K, Puschhof J, Breugem TI, Ravelli RBG, Paul van Schayck J, Mykytyn AZ, Duimel HQ, et al: SARS-CoV-2 productively infects human gut enterocytes. Science 369: 50-54, 2020.

28. Kaushik A, Gupta S, Sood M, Sharma S and Verma S: A systematic review of multisystem inflammatory syndrome in children associated with SARS-CoV-2 infection. Pediatr Infect Dis J 39: e340-e346, 2020.

29. Balasubramanian S, Nagendran TM, Ramachandran B and Ramanan AV: Hyper-inflammatory syndrome in a child with COVID-19 treated successfully with intravenous immunoglobulin and tocilizumab. Indian Pediatr 57: 681-683, 2020.

30. Rauf A, Vijayan A, John ST, Krishnan R and Latheef A: Multisystem inflammatory syndrome with features of atypical kawasaki disease during COVID-19 pandemic. Indian J Pediatr 87: 745-747, 2020.

31. Acharyya BC, Acharyya S and Das D: Novel coronavirus mimicking kawasaki disease in an infant. Indian Pediatr 57: 753-754, 2020.

32. Lin JE, Asfour A, Sewell TB, Hooe B, Pryce P, Earley C, Shen MY, Kerner-Rossi M, Thakur KT, Vargas WS, et al: Neurological issues in children with COVID-19. Neurosci Lett 743: 135567, 2021.

33. Dufort EM, Koumans EH, Chow EJ, Rosenthal EM, Muse A, Rowlands J, Barranco MA, Maxted AM, Rosenberg ES, Easton D, et al: Multisystem inflammatory syndrome in children in New York State. N Engl J Med 383: 347-358, 2020.

34. Park A and Iwasaki A: Type I and III interferons-induction, signaling, evasion, and application to combat COVID-19. Cell Host Microbe 27: 870-878, 2020.

35. Blanco-Melo D, Nilsson-Payant BE, Liu WC, Uhl S, Hoagland D Møller R, Jordan TX, Oishi K, Panis M, Sachs D, et al: Imbalanced host response to SARS-CoV-2 drives development of COVID-19. Cell 181: 1036-1045.e9, 2020.

36. Panigrahy N, Policarpio J and Ramanathan R: Multisystem inflammatory syndrome in children and SARS-CoV-2: A scoping review. J Pediatr Rehabil Med 13: 301-316, 2020. 